\title{
CONTRIBUTION OF SATELLITE ALTIMETRY DATA IN GEOLOGICAL STRUCTURE RESEARCH IN THE SOUTH CHINA SEA
}

\author{
Tran Tuan Dung ${ }^{\mathrm{a}, *}$, Ho Thi Huong Mai ${ }^{\mathrm{b}}$ \\ ${ }^{a}$ Institute of Marine Geology and Geophysics \\ Vietnam Academy of Science and Technology \\ ${ }^{b}$ Institute of Economics \\ Ho Chi Minh National Academy of Politics \\ trantuandung@yahoo.com
}

Commission VIII, WG VIII/9 - Coastal and Ocean Applications

KEYWORDS: South China Sea; satellite altimeter data, marine gravity data; fault system; seafloor spreading axis; oceanic crust.

\begin{abstract}
:
The study area is bordered on the East China Sea, the Philippine Sea, and the Australian-Indo plate in the Northeast, in the East and in the South, respectively. It is a large area with the diversely complicated conditions of geological structure. In spite of over the past many years of investigation, marine geological structure in many places have remained poorly understood because of a thick seawater layer as well as of the sensitive conflicts among the countries in the region.

In recent years, the satellite altimeter technology allows of enhancement the marine investigation in any area. The ocean surface height is measured by a very accurate radar altimeter mounted on a satellite. Then, that surface can be converted into marine gravity anomaly or bathymetry by using the mathematical model. It is the only way to achieve the data with a uniform resolution in acceptable time and cost. The satellite altimetry data and its variants are essential for understanding marine geological structure. They provide a reliable opportunity to geologists and geophysicists for studying the geological features beneath the ocean floor. Also satellite altimeter data is perfect for planning the more detailed shipboard surveys. Especially, it is more meaningful in the remote or sparsely surveyed regions.

In this paper, the authors have effectively used the satellite altimetry and shipboard data in combination. Many geological features, such as seafloor spreading ridges, fault systems, volcanic chains as well as distribution of sedimentary basins are revealed through the 2D, 3D model methods of interpretation of satellite-shipboard-derived data and the others. These results are improved by existing boreholes and seismic data in the study area.
\end{abstract}

\section{INTRODUCTION}

A new approach in marine investigating is the application of remote sensing technology. The surface of the ocean is an imitation of the oceanfloor topography. Bumpiness of the ocean surface is caused by a small variation of gravity field of the earth. The topography of the ocean surface can be exactly measured by microwave radar altimeter mounted on a satellite. Satellite altimetry is providing the ocean surface height (Geoid height). Satellite altimetry-derived gravity and bathymetry can be received by transformation of satellite altimeter data using physical laws and mathematic models. The accuracy as well as resolution of the satellite altimeter data depends on the spatial coverage of the satellite tracks. And they have been improved over years by repetitive measurement (Sandwell D. T., Garcia E., Soofi K., Wessel P., and Smith W. H. F, 2013; Green Christopher M., Derek Fairhead and Stefan Maus, 2004). In marine investigation, satellite altimetry is the only way to achieve the data with a uniform resolution and in acceptable time and cost, especially for remote and sensitive conflict regions. The oceanographers, geologists, geophysicists using satellite altimeter data and its variants to study the earth's interior, mineral exploration, navigation etc. In the South China Sea (East Vietnam Sea), in spite of over the past many years of investigation, many marine places have not been surveyed or only worked in a very sparse grade, especially for deep basins with a thick seawater layer and remote areas. Fortunately,

\footnotetext{
* Corresponding author.
}

satellite altimeter data is effectively exploited to fill the gap in data of shipboard survey (Sandwell D. T., Garcia E., Soofi K., Wessel P., and Smith W. H. F, 2013; Green Christopher M., Derek Fairhead and Stefan Maus, 2004; Tran Tuan Dung et al., 2002, 2003, 2013).

The satellite altimeter data is collected by Geosat and ERS-1,2 and Topex/Poseidon altimeters over many last years. From 1980's up to now, many authors have been trying to improve the accuracy and resolution of the satellite altimetry-derived data. Sandwell and Smith (2009, 2013) and GETECH (1996) using the satellite altimeter data, which is measured by Geosat and ERS-1, 2 and have produced a gravity and bathymetric grid with interval of 1'x1' (V23.1) for most the ocean all over the world (Sandwell D. T., Garcia E., Soofi K., Wessel P., and Smith W. H. F, 2013; Green Christopher M., Derek Fairhead and Stefan Maus, 2004).

In this paper, the authors have used and combined the satellite altimetry data and shipboard data in order to bring out the satellite-shipboard-derived data with a higher accuracy and uniform resolution for the South China Sea (East Vietnam Sea). Some interpretative methods of satellite altimetry-derived data such as finite difference, horizontal gradient, isostatic residual etc., are applied here to highlight the geological features in the region.

\section{OVERVIEW ON SATELLITE ALTIMETRY}

Since the 1980's satellites have been used to map the sea surface height variations using radar pulse. Satellite altimetry is providing better measurements of the sea surface height and its 
associated gravity field. The ocean surface would not be flat (ignore waves, winds, tides and currents), but according to the physical laws, it is an equipotential surface of the earth's gravity field. On a global scale, many studies have indicated that there is about of 100 meters different between the actual surface of the ocean and the standard ellipsoid. The roughness (bumps and dips) of the ocean surface is caused by a fluctuation of the earth's gravity field. These bumps and dips cannot be seen with the naked eye but can be measured by very accurate radar mounted on a satellite.

It is necessary to measure precisely two distances in order to establish the ocean surface topography. First, the height of the satellite above the ellipsoid $h *$ is measured by a global network of Laser and Doppler stations placing on the earth surface. The trajectory and height of the satellites are further refined by using dynamic orbit calculations. Second, the height of satellite above the closest ocean surface $h$ is measured by microwave radar with carrier frequency of $13.5 \mathrm{GHz}$ (GeoSat), $13.5 \mathrm{GHz}$ (ERS$1,2)$. A high repetition rate of radar pulse is used to denoise and increase reflection signals (1000 pulses/second). The satellite generated radar pulses every $\sim 1 / 1000$ second giving radar reflection signals at $1 / 20$ s intervals for ERS- 1 (every $300 \mathrm{~m}$ along track) and $1 / 10$ s for GeoSat (every 600m along track). Effects of the tide, electrolytic dissociation atmosphere are corrected in calculating process as well. The ocean surface height $N$ (Geoid height) relative to the ellipsoid is the difference between these heights (see fig. 1). The $N$ can be measured at a vertical resolution of $0.03 \mathrm{~m}$, as follows (Sandwell D. T., Garcia E., Soofi K., Wessel P., and Smith W. H. F, 2013; Green Christopher M., Derek Fairhead and Stefan Maus, 2004):

$$
N=h^{*}-h
$$

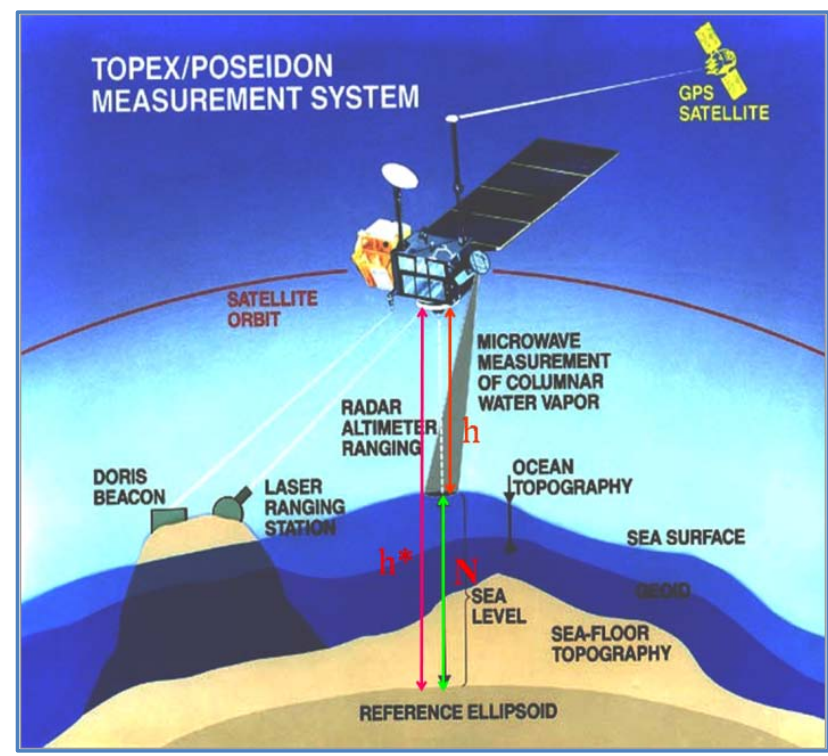

Figure 1. Measurement of Ocean Surface Height by Topex/Poseidon System

\section{DATA USED}

In order to improve the accuracy and resolution of the satellite altimetry-derived data, we compared and combined the satellite data and shipboard data that are available in the area (Geosat, ERS-1/2, Topex/Poseidon satellites and Gagarinsky, Attalante vessel's). In this study, we use the satellite altimetry-derived data that provided by Sandwell D. T., with 1'x 1' grid interval (V23.1) (Sandwell D. T., Garcia E., Soofi K., Wessel P., and Smith W. H. F, 2013).

The accuracy and resolution of satellite-derived data depend on a variety of factors including typical sea state and proximity to land. Also, they are much depended on the quality and quantity of the shipboard data. For that reason, we have selected and only used the shipboard profiles that have an obvious origin, high accuracy and reliability to carry out the works. The shipboard data measured by Gagarinsky and Attalante vessels are selected for our study. In the area, the density of the measured profiles in the shallow water is denser than that in the deep-water region (Sandwell D. T., Garcia E., Soofi K., Wessel P., and Smith W. H. F, 2013; Green Christopher M., Derek Fairhead and Stefan Maus, 2004; Tran Tuan Dung et al., 2003, 2013; Smith W. H. F and D. T. Sandwell, 1994).

\section{METHODS}

\subsection{Comparison and combination of satellite-derived and shipboard data}

We have used 45 shipboard profiles and extracted 45 satellite altimetry-derived profiles, which are coordinately coincided to each other respectively, for the comparison. But herein, only 12 profiles compared are presented in fig. 2. The red lines show shipboard profiles, the blue lines show satellite altimetryderived profiles. To evaluate the accuracy of profiles compared we calculate the RMS difference between the each satellite altimetry-derived profile and shipboard profile respectively.

The satellite altimetry-derived data is constrained by shipboard data using finite difference and minimum curvature methods. As a result of the study, after carrying out the works, the authors have produced a uniform grid of the combined satellite-derivedshipboard data (gravity anomaly, bathymetric map) with a reliable accuracy, which is consistent with many geological, geophysical studies such as geotectonics, crustal structure and oil-gas exploration for the whole South China Sea (East Vietnam Sea) (fig. 3, 4).

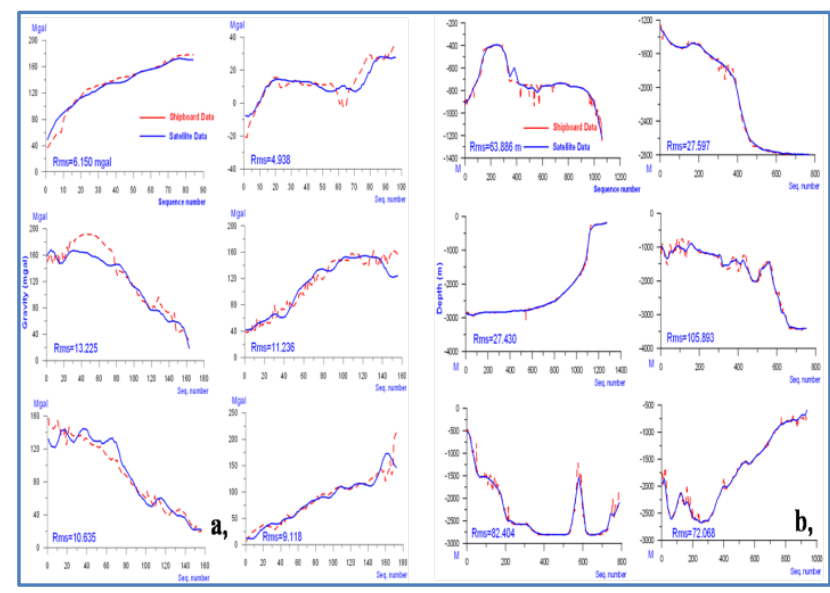

Figure 2. Comparison of shipboard data (dashed lines) and satellite altimetry-derived (solid lines); a> satellite-derived and shipboard gravity profiles; b> Satellite-derived and shipboard depth profiles;

\subsection{Some satellite-derived data interpretative methods}

In this paper, the authors do not intend to go to the detail of satellite altimeter-derived data interpretative methods, only mention generally to some the achieved results. Here, we have applied the advanced methods, which are edge enhancement, directional filtering, isostatic, maximum gravity gradient etc., to interpret the satellite altimeter-derived data with the purpose is to show up the geological features in the upper part of the 
Earth's crust in the South China Sea (Tran Tuan Dung et al., 2002, 2003, 2013).

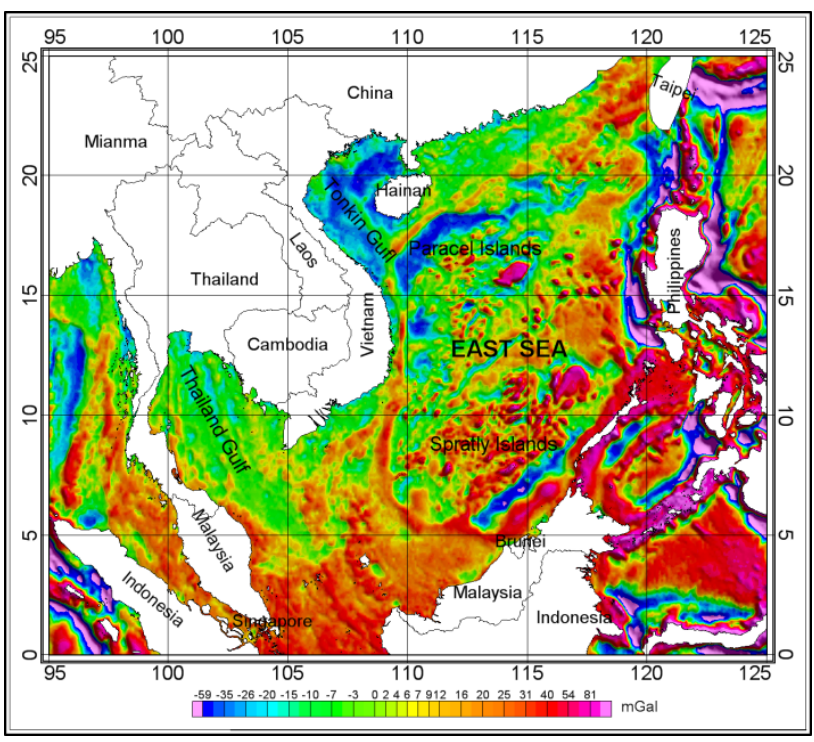

Figure3. Satellite-derived gravity anomaly (combined from satellite altimetry-derived and shipboard data)

\section{RESULTS}

Most of the regional geological features such as the seafloor spreading ridges, fault system, variation of continental, transitional and oceanic crust, the seamounts as well as volcanic chains are clearly manifested in the variants of satellite altimeter-derived data (see fig. 4, 5, 6).

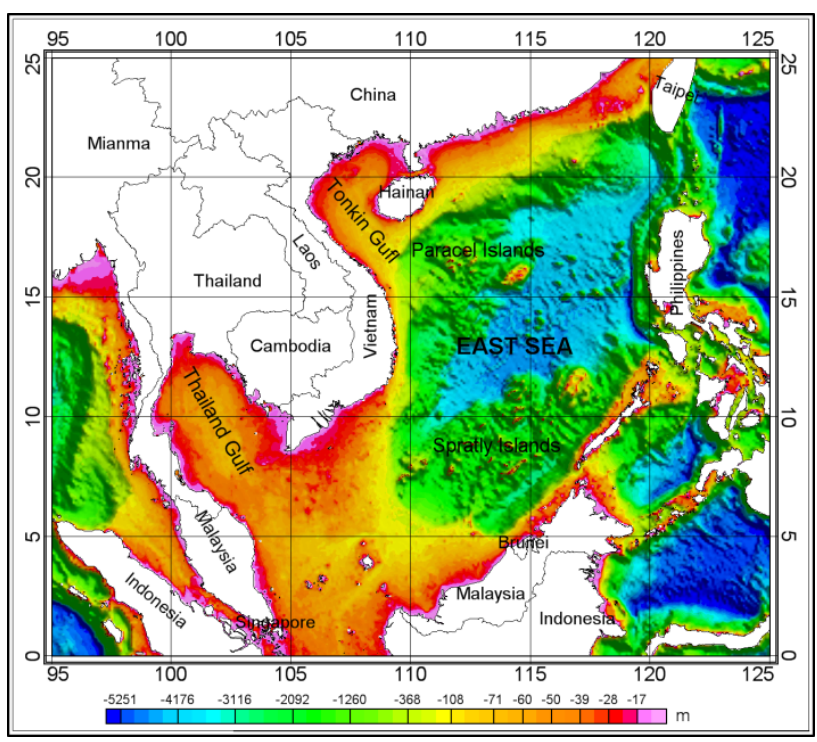

Figure 4. Satellite-derived bathymetry (combined from satellite altimetry-derived and shipboard data)

\section{CONCLUSION}

- In the South China Sea, satellite altimetry is the only way to achieve the data with a uniform resolution and in acceptable time and cost, especially for remote and sensitive conflict regions.

- Satellite altimeter data can be converted into marine satellite altimetry-derived gravity and bathymetric data by using physical laws and mathematic models. Marine geophysicist and geologists can use these data to study the earth's interior.

Comparison and combination of the satellite altimetryderived and shipboard data is a best way to improve the accuracy and resolution of marine satellite altimetry data. It contributes effectively towards the marine investigation.

- Integration of satellite altimetry and marine geophysics is a new approach that consists with many geological, geophysical studies such as prediction of bathymetry, geotectonics, crustal structure and oil-gas exploration in the ocean, especially in the deep-water regions.

- $\quad$ Satellite altimetry contributes greatly towards the reduction of time as well as expenses and gives support to a more detailed planning for the shipboard surveys. Moreover it is also useful at other fields such as navigation, plate tectonics, undersea volcano and lithospheric structure in the South China Sea (East Vietnam Sea).

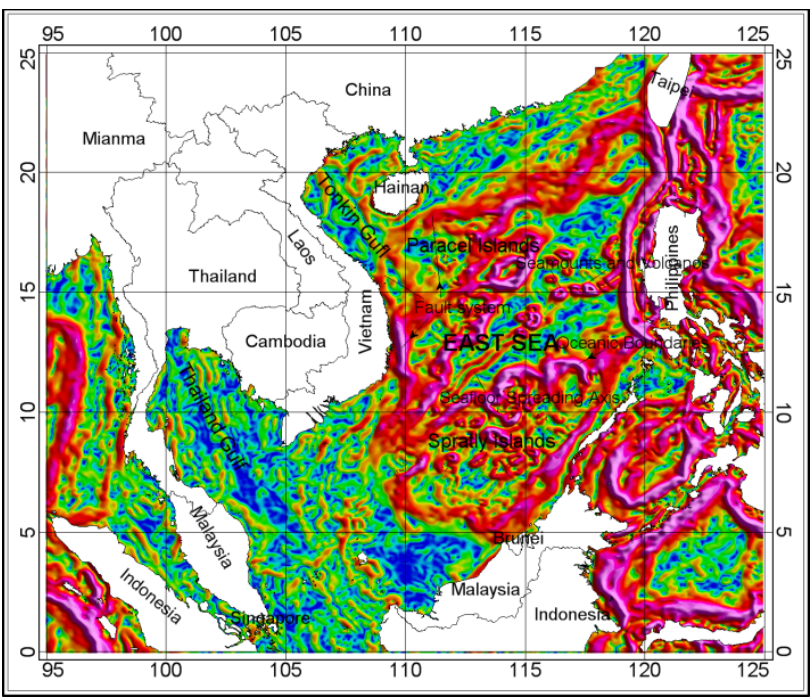

Figure 5. Showing seamounts, volcanoes, spreading ridges, fault systems on the oceanfloor (from the horizontal gradient of satellite-derived gravity anomaly)

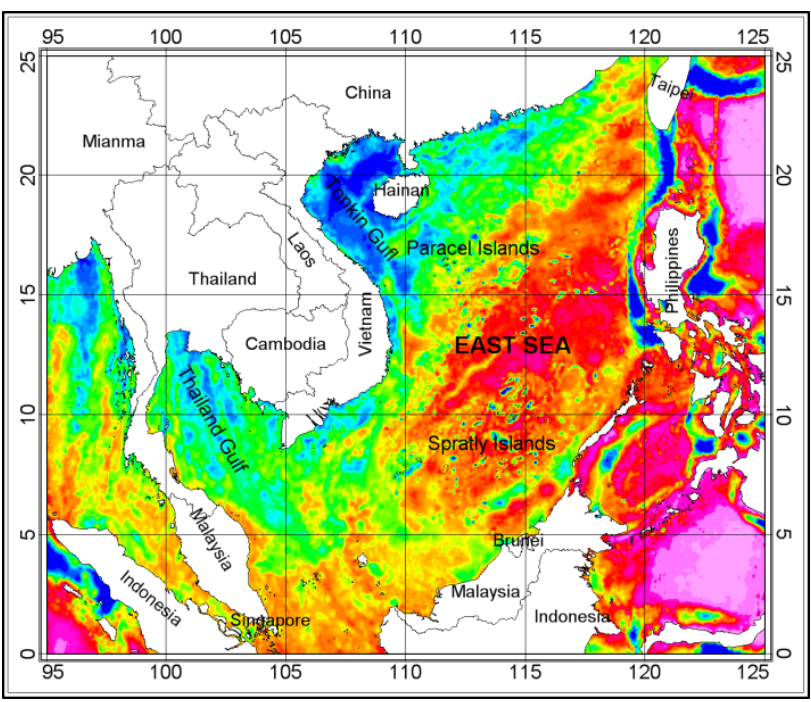

Figure 6. Showing the continental, transitional and oceanic crust and sedimentary basins (from satellite-derived isostatic residual gravity anomaly) 


\section{ACKNOWLEDGEMENTS}

The authors wish to thank the VAST's Project No. VAST06.06/16-17 for funding this research.

\section{REFERENCES}

Derek Fairhead J., Christopher M. Green and Mark E. Odegard. Satellite-derived gravity having an impact on marine exploration. The leading Edge, August, 2001.

Green Christopher M., Derek Fairhead and Stefan Maus. Satellite-derived gravity: Where we are and what's next. GETECH, University of Leeds, UK. 2004.

Sandwell D. T., Garcia E., Soofi K., Wessel P., and Smith W. H. F, 2013, Towards 1mGal Global Marine Gravity from CryoSat-2, Envisat, and Jason-1, The Leading Edge, 32(8), 892899. doi: 10.1190/tle32080892.1.

Simpson, R. W., R.C. Jachens, R.J. Blakely, and R.W. Saltus. A new Isostatic Residual Gravity Map of the Conterminous United States With a Discussion on the Significance of Isostatic Residual Anomalies. J. Geophys. Res., vol. 91, pp. 8348-8372. 1986.

Smith W. H. F and D. T. Sandwell. Bathymetric prediction from dense satellite altimetry and sparse shipboard bathymetry, $J$. Geophys. Res.,vol. 99, pp. 21803-21824, 1994.

Tran Tuan Dung et al,.Bathymetric prediction for oceanography and marine geophysics - an application of remote sensing in the East Vietnam Sea deep basin. Journal of Marine Science and Technology, Vol. 4, Vietnam, 2002.

Tran Tuan Dung, Trinh Hoai Thu. Application of satellite altimeter data in studying geological structure in the East Vietnam Sea deep basin. Proceeding of Symposium on Advances in Microwave Remote Sensing Application. Indian Institute of Technology, Bombay, India, 2003.

Tran Tuan Dung. Isostatic anomaly and gradient of the gravity anomaly associated with the tectonic structural elements in the East Vietnam Sea. Science and Technics Publishing House. Hanoi. Vol.7, pp. 119-125. 2003.

Tran Tuan Dung, Bui Cong Que, Nguyen Hong Phuong, 2013. Cenozoic basement structure of the South China Sea and adjacent areas by modeling and interpreting gravity data. Russian Journal of Pacific Geology. ISSN 1819-7140. Vol. 4. Pp. 227-236.

Yale M. M., D. T. Sandwell and A. T. Herring. What are the limitations of satellite altimetry?. The Leading Edge, January, 1998, pp. 73-76. 